\title{
Fidelino de Figueiredo, a Sociedade Portuguesa de Estudos Históricos e a Revista de História: ambiente científico e horizontes historiográficos (1911-1928)
}

\author{
Fidelino de Figueiredo, the Sociedade Portuguesa de Estudos Históricos \\ and the Revista de História: scientific environment and historiographic \\ horizons (1911-1928)
}

\author{
Ricardo de Brito \\ ricardobritsz@gmail.com \\ Doutorando PIUDHist \\ Centro de História da Universidade de Lisboa \\ Cidade Universitária, Alameda da Universidade \\ 1600-214 - Lisboa \\ Portugal \\ Nuno Bessa Moreira \\ knunoclio@gmail.com \\ Doutor em História \\ Faculdade de Letras da Universidade do Porto \\ Via Panorâmica, s/n \\ 4150-564 - Porto \\ Portugal
}

\section{Resumo}

Michel de Certeau, na obra $A$ escrita da história, de cuja primeira edição se comemoraram recentemente, em 2015, 75 anos, chama a atenção para a importância dos lugares do historiador, das práticas e da escrita historiográficas. Neste artigo, a Sociedade Portuguesa de Estudos Históricos (SPEH) e o seu órgão, a Revista de História, assumem tais lugares, impulsionados, em larga medida, pelo labor de Fidelino de Figueiredo, personalidade primacial na criação e institucionalização da SPEH e da publicação citada e que, em 1910, com 22 anos, publicou $O$ espírito histórico, obra que constituiu o arranque epistemológico e simbólico, mas também a seiva das iniciativas referidas. A SPEH e o opúsculo fideliniano serão abordados num primeiro momento deste artigo. Na segunda parte, procura-se analisar os conceitos historiográficos operatórios plasmados no periódico que fazem a ponte entre práticas e escritas historiográficas, configurando discursos e representações, exibindo a tensão entre a prevalência de uma historiografia erudita e tradicional, mais rankeana do que inspirada na escola metódica, e a necessidade de afirmação do espírito histórico nacional, ao arrepio do positivismo e do republicanismo radical.

\section{Palavras-chave}

Sociedade Portuguesa de Estudos Históricos; Historiadores; Historiografia.

\begin{abstract}
In his famous book Writing of History - whose first edition was recently celebrated for its 75th anniversary -, Michel de Certeau draws attention to the importance of the historian locus, of the practices and of the historiographical writing. In this paper, such locus is the Sociedade Portuguesa de Estudos Históricos and its journal, Revista de História. Largely driven by the work of Fidelino de Figueiredo, pivotal actor for the creation and institutionalization of both the society and its journal, he published in 1910, at the age of 22, O Espírito Histórico, which marked his epistemological and symbolic breakthrough. The second part of this paper analyzes the historiographical and operational concepts embodied by the Revista de História, which bridge the gap between practices and historiographical writings, shaping discourse and representation, showcasing the tension between the prevalence of classical historiography - more linked to Ranke than inspired by the methodical school - and the need to consolidate a national historical spirit, in defiance of positivism and radical republicanism.
\end{abstract}

\section{Keywords}

Sociedade Portuguesa de Estudos Históricos; Historians; Historiography.

Enviado em: 21/10/2016

Aprovado em: 19/12/2017 


\section{Da crítica historiográfica e social à génese da Sociedade Portuguesa de Estudos Históricos: $\boldsymbol{O}$ espírito histórico e a afirmação individual}

Por volta de 1950, decorridas mais de duas décadas da extinção da Sociedade Portuguesa de Estudos Históricos (SPEH), Fidelino de Figueiredo publicou na Revista de História da Universidade de São Paulo uma interessante síntese da historiografia portuguesa da primeira metade do século XX. Entre as principais dinâmicas historiográficas e de historiadores que decidiu evidenciar, incluiu, obviamente, a relativa ao momento de formação da SPEH, o que serviu, também, como forma de agradecimento a quem, naquela época, respondera positivamente ao seu apelo: "Só agora, tantos anos depois, eu meço toda a extensão da bondade e confiança dos homens ilustres, que prontamente acudiram ao chamamento duma voz moça e sem autoridade" (FIGUEIREDO 1954 , p. 336). De fato, quando Fidelino publicou a primeira edição d'O espírito histórico (1910), poucos dias após a revolução republicana (5 de outubro de 1910), contava apenas com 20 e poucos anos; a "voz moça e sem autoridade" dava assim início a um percurso que o levaria a trilhar uma significativa trajetória no campo da história da literatura e da crítica literária, legando à posteridade importantes contributos. Será, portanto, possível considerar que, de alguma forma, a escrita d' $O$ espírito histórico (que já continha a embrionária ideia de uma sociedade de historiadores) teria servido tanto como uma crítica ao processo revolucionário então em curso como, igualmente, uma forma de afirmação pessoal e científica? Certamente. Aliás, não foi por acaso que, em 1930, no prefácio de História dum "Vencido da vida", procedeu a uma lacônica síntese dos anos de afirmação (e formação) como historiador e crítico literário: "Poderia mesmo levar os nomes de dois colaboradores: Fidelino de Figueiredo (1913-14) e Fidelino de Figueiredo (1928)" (FIGUEIREDO 1930, p. 9-10). Dessa forma revelava que, retrospectivamente, fazia um exercício de interpretação da sua figura como historiador ou "cidadão" socialmente interventivo. Foquemonos, então, no "primeiro" Fidelino.

O ensaio $O$ espírito histórico, ${ }^{1}$ texto inserido numa concepção autoral maior, a Biblioteca de Estudos Históricos Nacionais, ${ }^{2}$ assumiu-se como o principal «manifesto» de intervenção de Fidelino neste período, ${ }^{3}$ que revelava na obra as suas principais posições historiográficas e de visão da sociedade. Comportava, genericamente, duas dimensões essenciais: uma inicial, de teor problemático, em que colocava em debate a posição dos estudos históricos e a função social que estes poderiam (e deveriam) desempenhar no tempo presente; e uma segunda, em que Fidelino se debruçou sobre a História como disciplina

\footnotetext{
${ }^{1}$ Este texto teve três edições (1910,1915 e 1920). Embora, ao comparar as diferentes edições, se possam registrar nuances distintivas, em alguns casos substanciais e que refletem uma evolução no pensamento de Fidelino (para além de uma melhor clareza de suas ideias), optou-se por utilizar, essencialmente, a $1^{a}$ edição, que precede a criação da SPEH.

2 O próprio Fidelino de Figueiredo admite uma clara influência de Oliveira Martins em prefácio à obra deste, História da civilização Ibéria: "Logo em 1910 foi uma reminiscência da sua Biblioteca de Ciências Sociais que sugeriu a minha Biblioteca de Estudos Históricos Nacionais".

3 O primeiro foi, segundo A. Soares Amora, Arte moderna - miragem e crítica (1908), focado essencialmente em aspectos ligados à literatura.
} 
científica. No entanto, na $1^{\mathrm{a}}$ edição, ${ }^{4}$ em que podemos logo detectar reticências quanto ao positivismo, o autor sentiu a necessidade, no campo das reflexões epistemológicas, de fazer uma distinção (ou delimitação), algo confusa, digase, entre Sociologia e História. Dando Fidelino o exemplo de vários autores que procuravam estruturar a sociologia como ciência (Spencer, Simmel, Bouglé, Giddings, Durkheim, Palante), chega às seguintes considerações: i) tendo em conta o seu objeto de estudo, a sociologia não pode ser incluída no campo das ciências matemáticas; ii) para inclui-la nas ciências da natureza, primeiro seria preciso definir claramente o papel do homem como "criador de força"; iii) por último, a sociologia ainda se encontra muito longe de conseguir leis científicas para o seu campo de estudo (CARNEIRO 2004, p. 17).

Num segundo momento, ao se debruçar sobre a ciência histórica, Fidelino criou um texto bastante atualizado, para a época, nos campos teórico e metodológico. As suas orientações e influências tinham por base a epistemologia finissecular alemã, de matriz neokantiana, a escola metódica de Langlois e Seignobos, a síntese histórica de Henri Berr e as concepções filosóficas de Benedetto Croce. Depois de principiar a sua análise de História com a definição de Michelet segundo a qual "a história é a ressurreição do passado", definição esta que consegue conjugar o essencial dos múltiplos conceitos de história, ${ }^{5}$ Fidelino delimita desde logo o objeto de estudo da história:

Um agregado de instituições parciais, famílias, classes, isto é, uma simbiose de consciências cria, pela sua inter-acção, um estado particular e específico, cujas actividades de pensamento, de sentimentos e de vontade são distintas das formas correspondentes da actividade individual, visto que são conformes ao interesse comum. Essa actividade passa-se no tempo, determina actos e transformações morfológicas. Reconstruir esse evoluir no tempo, eis o objecto da história (FIGUEIREDO 1910, p. 25).

A reconstrução que Fidelino refere só é possível mediante um delicado processo em que o documento é tra.nsformado em fato. $O$ documento, apesar de transformado em fato histórico, não constitui, ainda, uma realidade histórica. Para que se opere a reconstrução da realidade histórica, permitindo construir a visão mais verdadeira de uma determinada época, o historiador deve proceder à síntese histórica (Henri Berr). Quanto mais numerosos e verdadeiros forem os fatos, mais aproximativa da realidade se torna a síntese: "Tal é o fim da história" (FIGUEIREDO 1910, p. 25). Perante esta construção de síntese do passado, o historiador depara-se com um conjunto de fatos que não se repetem, mas que se sucedem no tempo, existindo, portanto, um nexo de causalidade na sucessão dos fatos históricos:

Na construção sintética o historiador encontra-se perante fatos, que não se repetem, mas se sucedem no tempo, determinando-se de antecedente

\footnotetext{
${ }^{4} \mathrm{~A}$ parte referente à sociologia desaparece nas edições seguintes.

${ }^{5}$ Fidelino refere que "Varie-se infinitamente o sentido e o processo da ressurreição, restrinja-se ou alargue-se a noção de passado, ponha-se nessa ressurreição um desejo maior ou menor de verdade, junte-se, atenuese, reforce-se ou retire-se-Ihe a preocupação ethica, e, fazendo todas as permutas possíveis, teremos todos os conceitos de história, que a humanidade se formou" (FIGUEIREDO 1911, p. 24).
} 
em consequente, e por isso procura não a lei relacional que fixa a rítmica, mas o nexo de causalidade nesta sucessão (FIGUEIREDO 1910, p. 26).

Isto faz com que a história se afaste, completamente, das ciências matemáticas e naturais, na medida em que não é possível a criação de leis que consigam prever fatos: "Afirmam o contrário aqueles que, por falsas analogias, aproximam a história das ciências naturais, quando elas se opõem de forma mais flagrante" (FIGUEIREDO 1910, p. 26). Todavia, Fidelino não descartava a possibilidade de formulação de uma lei. Sendo contra a construção de leis históricas, leis de repetição que possibilitam a previsão, propõe uma lei que explique o progresso da história. Estaremos perante uma contradição? Não propriamente, pois, como sugere, procurava-se a lei do progresso, "porque se pretende uma só [lei], a que rege esse contínuo variar, e não exprimir uma regularidade de repetição, como nas ciências da natureza" (FIGUEIREDO 1910, p. 28).

A separação entre história e as demais ciências naturais foi uma das principais ideias de Fidelino, que criou, para ilustrá-la, um quadro com as diferenças entras elas: "enquanto as ciências naturais estudam o que é geral e susceptível de se observar nessa generalidade, a história estuda o individual", perspectivando na sua análise a "noção de valor", um outro conceito estranho às ciências naturais. ${ }^{6}$ Estamos, portanto, perante uma perspectiva axiológica do estudo da história. Mais à frente, Fidelino voltará a desenvolver esta ideia apoiando-se num dos seus principais autores de referência, Benedetto Croce. Duas características fundamentais do pensamento do historiador italiano são logo evidenciadas, a da subjetividade do historiador e a da filosofia:

B. Croce assegura mesmo que é necessária essa atitude subjectiva, porque sem um ideal social, ainda que pessoal, o historiador não atinge mais do que análises sem vida, amputadamente. É para desejar a atitude objectiva neste sentido: o historiador deve ser imparcial, nem arbitrário, nem apaixonado, mas deve ter um ideal social, uma vista filosófica de conjunto (FIGUEIREDO 1910, p. 31).

No pensamento de Fidelino o individual assume preponderância quando da construção da síntese histórica em função de um outro fator que ele cria para distinguir o conhecimento histórico das ciências naturais, o acaso: "é isso a acidentilidade histórica: a inovação individual, e o encontro de duas séries de fenómenos num ponto tal, que a sua resultante modifica por completo o curso normal das coisas, o acaso" (FIGUEIREDO 1910, p. 28). É reveladora neste aspecto a influência de Oliveira Martins, que também assinalou o acaso

\footnotetext{
${ }^{6}$ Ao propor tal definição, apresenta outras duas concepções, a de Spencer e Lacombe. Quando refere Spencer, Fidelino crítica a forma como esse autor restringe o progresso à evolução contínua do homogêneo para o heterogêneo, relegando o papel do indivíduo para uma «não existência» ao centrar-se no primado das instituições: "fez mais sociologia do que história", concluirá Fidelino. Quando explana o pensamento de Lacombe, que propõe o conflito como lei do progresso, Fidelino afirma, na $1^{\text {a }}$ edição de sua obra, que "é muito mais histórica e esclarece-nos muito mais". Porém, na $2^{a}$ edição, p. 46, mantendo a crítica a Spencer, o autor irá mudar a sua opinião em relação a Lacombe: "O sr. Lacombe propôs a lei do conflito, que é menos destituída de sentido histórico que a de Spencer, mas que é muito deficiente; assenta só sobre a consideração do modo de ser episódico desse progresso, conseguido muito por conflito, elucidando escassamente, como se vê" (FIGUEIREDO 1910, p. 26).
} 
na história. Surge-nos, pois, a pertinente pergunta: é a história uma ciência? Segundo Fidelino, esta pode ser considerada uma ciência, pois o seu grande fim é a procura da verdade e nessa investigação utiliza métodos rigorosos de análise. Mas, adverte, é uma ciência sui generis, ou seja, única no seu género, pois "busca atingir uma verdade temporal e concreta, insusceptível por isso de formular leis e de prever" (FIGUEIREDO 1910, p. 30), além de não excluir acrescente-se - a subjetividade de pensamento do historiador, algo estranho às ciências exatas. Todavia, a história não é uma ciência sui generis porque o seu objeto de estudo é particular ou porque o historiador tem de atender a um conjunto de fatores que não encontramos nas ciências naturais. É sui generis porque, como refere Fidelino, certamente influenciado por Croce, "também é arte, porém arte sui generis. O artista tem por fim fazer arte; o historiador faz história, isto é, verdade por meio da arte" (FIGUEIREDO 1910, p. 30). Portanto, a história, como ciência, não deixa de possuir um determinado rigor no método utilizado através das operações heurísticas; porém, a apresentação dos resultados por parte do historiador já dependeria da sua subjetividade e talento para construir a síntese, e, nesse sentido, o historiador criaria arte.

O que Fidelino de Figueiredo apresenta neste capítulo dedicado ao estudo da história é uma proposta que se opõe à perspectiva positivista e que adere com reservas à metódica, sendo essas as duas perspectivas dominantes na época. Em relação à primeira, Fidelino delimitou o conhecimento histórico em oposição às ciências naturais, indo contra a transposição, "por mera 30 analogia", dos princípios de investigação e de observação dessas ciências. Invariavelmente, a ideia em que Fidelino imprime maior relevo para justificar esta demarcação será a crítica à criação de leis históricas, uma operação impossível de realizar em sua opinião. Mas, sem criticar a utilização de métodos rigorosos, tal como proposta pela escola metódica, tentará imprimir uma nova linha orientadora ao trabalho final do historiador, mormente na questão da síntese, e evidenciando, mais de uma vez, que todo o historiador possui uma determinada subjetividade (B. Croce), uma determinada filosofia, que, através da sua escrita (arte), perpassará no seu trabalho.

Não obstante o interessante e pertinente estudo que Fidelino fez das mais recentes matérias teóricas e metodológicas no campo das ciências históricas na sua época, O espírito histórico revelava igualmente uma pertinente ligação entre o trabalho historiográfico e a função social que ele poderia desempenhar. Aliás, o texto principia precisamente nesse ponto. Numa «Justificação» preambular, afirma que a sociedade portuguesa no período anterior ao 5 de outubro se encontrava numa "paralisia apática", chegando a asseverar que os anos de transição de séculos não seriam objeto da história: "o essencial, em história, é a mudança e a intervenção pessoal, e estas não existiam" (FIGUEIREDO 1910, p. 3). Todavia, mesmo sem considerar que a instauração do regime republicano - ou uma mera mudança de regime - fosse a definitiva resolução dos problemas nacionais, viu o momento como uma oportunidade. A reorganização do ensino surgia como uma resposta fundamental, com uma preocupação especial dedicada à história, pois seria pela educação que germinaria o "gérmen do país 
futuro", e é nesse sentido que a ideia de espírito histórico ganha forma, com uma dimensão essencialmente pedagógica.

Figueiredo sustentou a ideia de que os estudos históricos, para além da sua componente de investigação, deviam repercutir-se socialmente como elemento aglutinador do grupo, mas com duas dimensões: por um lado, a ideia de que o estudo do passado poderia servir para uma nacionalização do país, porquanto Fidelino considerava que fora precisamente a "desnacionalização geral"7 que levara à decadência do povo português (e da realidade espanhola, igualmente), com "falta de seiva histórica" e "ignorante do seu passado". Por outro, o desenvolvimento do espírito histórico traria, pelo conhecimento do passado, uma visão mais serena dos problemas do presente, constituindo uma visão moderadora das transformações sociais e políticas. ${ }^{8}$ Dito de outro modo, o conhecimento histórico deveria ser usado como um mecanismo que permitisse um equilíbrio entre o pendor revolucionário abrupto ou um passadismo espectral e conservador e que, ao mesmo tempo, constituísse uma atitude de moderação no exercício político do poder. Estaremos perante a ideia de uma pedagogia da nação centrada na história? Sem dúvida. Como podemos observar, Fidelino oponha-se a mudanças bruscas, preferindo a via reformadora. A ideia de espírito histórico aparece mais clarificada na $2^{\mathrm{a}}$ edição:

Foi por esta forma [através dos estudos históricos], por solicitações de curiosidade científica, que nasceu o espírito histórico, que resumidamente consiste na consideração das variações temporais e das sucessões causais, quando se abeiram os problemas que respeitam ao homem, em sociedade, e que, por definição mais compreensiva significará a certeza sempre presente do império do passado, e duma maneira ainda mais geral o gosto pelos estudos do passado (FIGUEIREDO 1915, p. 8).

Concluída a análise de como os estudos históricos e a sua derivação para o espírito histórico tiveram uma importância significativa noutros países europeus (FIGUEIREDO 1910, p. 5-6), Fidelino iniciou a sua observação de como poderiam esses estudos influir na sociedade portuguesa. Os estudos de índole histórica deveriam contribuir para a transformação daquilo que apelidou de "psique nacional", que, segundo ele, se encontrava estagnada e atrasada. O suporte teórico desse conceito congregava os fatores econômicos, morais, intelectuais e políticos, que, em última análise, seriam aqueles que poderiam potencializar a efetiva transformação social através de um novo espírito colectivo. A questão psicológica da nação, ideia segundo a qual esta era vista como um organismo vivo, não era um tema novo. Fora, aliás, um assunto bastante debatido, com diferentes matizes, durante o século XIX, no qual podemos destacar Alexandre Herculano, J.P. Oliveira Martins (autores pelos quais Fidelino nutria grande

\footnotetext{
7 Por este motivo, na $1^{\text {a }}$ ed., no título do capítulo dedicado ao espírito histórico, Fidelino escreve «Espírito Histórico e o Espírito Nacional», que desaparece nas edições posteriores.

${ }^{8} \mathrm{~A}$ ideia do conhecimento histórico como mecanismo moderador nas transformações sociais encontra-se mais desenvolvida na $2^{a}$ edição. Porém, na $3^{a}$ ed, de 1920, Fidelino reconhece a falência dessa sugestão: "Cremos hoje, com bem maior realidade, que não é a historiografia que exerce considerável influxo social, mas que são as correntes políticas e sociais que imprimem cunho próprio aquela, a qual subordinando-se a elas com elas colabora ou, opondo-se-Ihes, também dela deriva como reacção", 3. ed. 1920, p. VII.
} 
respeito e admiração), Alberto Sampaio, Teófilo Braga, entre outros (MATOS 2008, p. 94-105). Fidelino apresentou um quadro em que conjugava os vários fatores que conduziram a seu ver ao estado decadente em que se encontrava a cultura portuguesa de então: uma massa que não desenvolvia o labor intelectual, delegando esse trabalho a uma pequena minoria. Esta minoria, por seu turno, praticava uma especialidade demasiado redutora ou, no extremo oposto, um enciclopedismo inconsequente. Por último, não qualquer trabalho desenvolvido possuía a necessária ligação com o meio social; Fidelino dava o exemplo dos artistas, que raramente conseguiam chegar ao público. Isto levou a que existisse uma intelectualidade fraca, uma educação essencialmente instrutiva sem um propósito educativo, ${ }^{9}$ determinando, em suma, a inexistência da "vista filosófica do seu meio".

Para a sociedade poder caminhar para um objetivo comum, imperava, pois, a necessidade de que reouvesse o conhecimento dos seus momentos pretéritos, voltando a ser possuidora da seiva histórica, de um espírito de nacionalidade. Era necessária a existência da causa que motivara o progresso noutros países, a da cultura científica. A sua proposta não podia ser mais clara:

Urge, pois, que na reforma da instrução superior, se crie um centro de estudos nacionais ou pelo menos, ainda que dispersos, estes tenham uma longa representação. [...] Era também da maior urgência, por ser da maior oportunidade e eficácia, a fundação de uma revista de história, onde se recolhessem todas as monografias, todos os elementos que contribuíssem para essa tarefa sagrada na nacionalização do país. O exemplo está dado. Em 1819 - após a revivescência que se seguiu aos desastres infligidos por Napoleão - fundou-se em Berlim uma Sociedade histórica, a que pertenceram, entre muitos outros, Niebuhr, Bruder Grimm, Savigny, Bruder, Schlegel, Ranke, etc. Insuflemos, pois, um espírito nacional e novo ao país que a si mesmo se deu uma forma nova (FIGUEIREDO 1910, p. 12).

O mote para a criação da Sociedade Nacional de História, posteriormente Sociedade Portuguesa de Estudos Históricos, estava dado, e o que Fidelino entendia por espírito histórico passava a ter uma oportunidade de manifestação e de desenvolvimento concreto.

\section{A vida associativa: uma breve síntese}

Em 1911, foi publicada a circular-programa que ilustrava, de forma pública, a fundação da SPEH e em que se expunha o essencial das suas bases programáticas. Enviada a "todos os profissionais portugueses de ciências históricas", foi assinada por quatro figuras: Fidelino de Figueiredo, Cristovão Magalhães de Sepúlveda, David Lopes e José Leite de Vasconcelos (Boletim da Sociedade de Geografia 1911, p. 120-125). Embora assinada por outras três figuras de grande prestígio à época, as semelhanças entre $O$ espírito histórico

\footnotetext{
9 "Durante todo o século XIX não houve uma só vez, na legislação portuguesa, um plano de educação nacional, segundo um espírito filosófico, em concordância com o espírito da sociedade, e mantendo-se nos vários graus da instrução, completo pela educação popular. Tudo tem sido desconexo e pondo de lado a função educativa da instrução" (FIGUEIREDO 1910 p. 11-12).
} 
e a circular-programa são flagrantes, o que nos leva a ponderar que tenha sido escrita inteiramente por Fidelino. Genericamente, ficam subentendidas algumas propostas aos subscritores: uma limitação dos danos causados pela revolução republicana ("revolução anti-histórica") e, no campo historiográfico, uma adequação dos estudos históricos portugueses aos modelos em voga nos países europeus que constituíam referências culturais. Concretamente: a) ativar os estudos históricos, mormente os nacionais; b) contribuir para a melhora do ensino educativo da história e do seu ensino superior; c) promover a ampliação do nosso ambiente científico, trazendo à discussão os modernos problemas das ciências históricas; d) concorrer para o estreitamento das relações desse ambiente com as sociedades, academiais e altas individualidades científicas estrangeiras. Como meios privilegiados para atingir esses fins, destacam-se as sessões periódicas; a publicação de uma revista; a conferência e a leitura pública; a divulgação de fontes originais; a colaboração com as instituições congêneres ou afins e com as escolas que tenham representação do ensino superior da história e ciências correlativas (Boletim... 1911, p. 125).

Rapidamente, a SPEH começou a funcionar. Embora, inicialmente, sem sede, realizaram-se mesmo assim sessões de debate e de leitura. Do período inicial saliente-se uma importante iniciativa: a enérgica defesa dos arquivos e outros acervos atingidos pela lei da separação da Igreja e do Estado (1911), mas sem grandes consequências (BRITO 2012, p. 41-42). Paralelamente, e à luz dos propósitos elencados, começou-se a pensar (para 1915) num audacioso Congresso Ibero-americano de História e Ciências Auxiliares, por ocasião dos centenários da tomada de Ceuta e da morte de Afonso de Albuquerque, mas que não chegou a se concretizar. ${ }^{10}$ Outros projetos, também interessantes e de significativo relevo científico, não chegaram a ver a luz do dia, embora tivessem tido algum impulso e lastro inicial. Foram os casos, até incentivados por Portaria do Governo (o que revelava uma certa importância que a SPEH tinha já granjeado), da organização de um Vade-mecum do investigador histórico e de uma Bibliografia histórica portuguesa (BRITO 2012, p. 50-55).

Ao longo dos vários anos de existência, a SPEH conseguiu congregar um significativo conjunto de sócios. No seu auge, chegou a ter mais de uma centena de associados. Figuras importantes a ela se associaram, como Damião Peres, Henrique da Gama Barros, João Lúcio de Azevedo, Queiroz Veloso, entre outros, incluindo figuras estrangeiras, como Edgar Prestage, Manuel de Oliveira Lima ou Charles Raymond Beazley. Observa-se certo equilíbrio geracional entre personagens com créditos já firmados, como Fortunato de Almeida ou José Leite de Vasconcelos e outros que, à época, começavam a ganhar projeção ou teriam um impacto importante no seu campo de estudos, como, por exemplo, Paulo Merêa, Francisco Vieira de Almeida ou até o próprio Fidelino. ${ }^{11}$

No estreitamento de relações com instituições ou acadêmicos estrangeiros, parece ter havido um relativo sucesso. Por exemplo, há notícia de permutas entre

\footnotetext{
${ }^{10}$ No entanto, chegou-se a projetar no papel a orgânica do evento. Veja-se o anexo 4 (BRITO 2012, p. 126-128) ${ }_{11}$ Para uma visão mais extensa do universo de sócios: BRITO 2012, p. 55-62. A lista completa de associados encontra-se nas p. 113-121.
} 
a SPEH e o Instituto Histórico do Rio de Janeiro ou a Academia de la Historia de Madrid (BRITO 2012, p. 43). No entanto, e na qualidade de secretário da SPEH, Fidelino alertou num relatório quanto a que esse estreitamento não tinha ainda sido totalmente bem-sucedido (pelo menos nos anos iniciais). Chegou mesmo a afirmar que se se pretendia organizar um meio científico capaz e com a participação de individualidades fora de Portugal, só se poderia contar na Europa com a participação de lusófilos e com alguns autores espanhóis. Fora da Europa, por razões históricas, o Brasil. As redes pessoais, contudo, permitiram que ao longo dos anos mais sócios (mas principalmente colaboradores da Revista de História) se juntassem à iniciativa.

Em suma, fruto da iniciativa de um então Fidelino "moço e sem autoridade", a SPEH congregou no seu seio uma elite intelectual significativa. Embora fossem assumidas programaticamente algumas posições ideológicas (um certo tipo nacionalismo ou posição contrária à ideia de progresso republicana), figuras de vários quadrantes, em alguns casos bastante divergentes, tiveram espaço nesse ambiente associativo. Mais: teve o mérito de consegui-lo num período bastante conturbado da vida portuguesa, a I República. Curiosamente, surgindo em reação à implantação do regime republicano, a SPEH durou sensivelmente o mesmo período. Não conseguiu, no entanto, levar avante algumas das suas principais iniciativas. Sem dúvida, o maior contributo científico que esta sociedade científica legou foi a Revista de História, à que daremos destaque seguidamente.

\section{O que fazem os historiadores quando fazem história? Conceitos historiográficos operatórios na Revista de História}

Neste "andamento" procederemos a uma síntese da forma como os colaboradores da seção de artigos do periódico dirigido por Fidelino de Figueiredo aplicaram certas coordenadas (MOREIRA 2013, p. 979-1023). Daí que a referência à Sociedade Portuguesa de Estudos Históricos adquira uma relevância primordial, uma vez que a Revista de História nasceu no seu seio e procurou executar, de modos diferentes ao longo do tempo, os princípios plasmados na circular fundadora da instituição que Ihe deu origem. A literatura, os descobrimentos ou a teoria da história (que constituía uma novidade), bem como a história política e diplomática, foram alvo de numerosos estudos na publicação. Evitando cair em anacronismos, convém referir estudos recentes que enfatizam a importância daquilo a que Herman Paul chama a scholarly persona dos historiadores, conjunto de virtudes, capacidades/competências, traços e disposições, sendo as primeiras epistémicas, cognitivas ou intelectuais (PAUL 2014, p. 348-371).12

\footnotetext{
12 Herman Paul confere um papel central às virtudes quando comparadas com os outros elementos da Scholarly Persona e, dentro daquelas, levanta mais as de caráter do que as epistémicas, expondo dez teses sobre a Scholarly Persona que devem ser vistas sobretudo como indicações de trabalho, sujeitas a adaptações várias, sempre no sentido de evitar incorrer em anacronismos ou presentismos. As teses são as seguintes: « Thesis 1: there is more at stake than styles of writing [...]; Thesis 2: Scholarly Personae are ideal-typical models of scholarly selfhood (...); Thesis 3: Scholarly Personae mold the self [...]; Thesis 4: Scholarly Personae embody qualities of virtue and skill [...]; Thesis 5: Virtues come with adjectives specifyng the goods they pursue $[\ldots .$.$] ; Thesis 6: Human beings, scholars included, are committed to multiple goods [...]; Thesis 7: Scholarly$
} 
Apesar de na publicação terem escrito mais de uma centena de estudiosos, nas várias seções (artigos, fatos e notas e bibliografia), Fidelino de Figueiredo assumiu sempre um papel preponderante. Ao que tudo indica, pode-se afirmar um sincretismo na Revista de História entre elementos que são herança da viragem arquivística, vigente desde meados dos Oitocentos, e a vontade de desenvolver competências de síntese, no plano cognitivo.

Os conceitos historiográficos operatórios permitem estabelecer pontes entre as práticas e os discursos e representações, na linha de Chartier. As coordenadas em análise são as seguintes: documento/monumento; fatos históricos, métodos; temporalidades; e verdade histórica, acrescentando-se um excurso sobre o modo biográfico. Nessa medida, aquelas dimensões são estudadas encarando as categorias num sentido kantiano, dado que não se prendem à razão absoluta, combinando-se entendimento e sensibilidade (MELO 2000). As varáveis consignadas configuram conceitos operatórios e, nos artigos escritos para a Revista de História, implicam-se mutuamente, não funcionando como entidades autônomas. ${ }^{13}$

\section{Documento/monumento}

Na seção de artigos da Revista de História, os historiadores dedicam-se à história como arremedo de forma científica da memória coletiva, concitando ambas dois tipos de matérias: os documentos e os monumentos. Convém ter presente a origem etimológica dos vocábulos "monumento" e "documento":

A palavra latina monuentum remete para a raiz indo-europeia men, que exprime uma das funções essenciais do espírito (mens), a memória (memini). O verbo monere significa fazer recordar, de onde avisar, iluminar. O monumentum é um sinal do passado [...] (LE GOFF 1981, p. 536).

Na publicação em análise, os usos romanos da palavra "monumento" primam essencialmente pela ausência. Os cultores de Clio que colaboram no periódico oscilam entre a publicação de documentos e a sua descrição e/ou crítica. Neste segundo caso, eles são utilizados enquanto fontes, que constituem elementos de prova que podem ser interpretados pelo historiador. Na Revista de História, o trabalho interpretativo é bem menos frequente do que o descritivo ou o explicativo. Em paralelo, convém empreender breve périplo pela etimologia do vocábulo "documento": "O termo latino documentum derivado de docere ensinar evoluiu para o significado de prova e é amplamente usado no vocabulário legislativo [...]" (LE GOFF 1981, p. 537).

Na Revista de História, o documento aparece muitas vezes como instrumento de educação dos leitores, ainda que tal desiderato surja, em diversas ocasiões,

\footnotetext{
Personae are embodied constellations of commitments [...]; Thesis 8: Scholarly Personae are contested and unstable [...]; Thesis 9: virtues and skills are rooted in desires wich are susceptible to manipulations [...]; Thesis 10: If Philosophy of History has the task of elucidating what it takes to study the past, then the persona of the historians should rank high on its agenda» (PAUL 2014, p. 348-371]).

13 Tomamos esta designação de conceitos operatórios de empréstimo à terminologia aplicada por Fernand Braudel à diacronia e à sincronia. Num sentido próximo, mas diverso daquele dos conceitos operatórios, Jacques Le Goff refere-se a «utensílios mentais», aplicando-os à história das mentalidades.
} 
elidido sob o manto da pretendida objetividade documental. Ora, no periódico dirigido por Fidelino de Figueiredo predomina um sentido restrito de documento e de prática documental, rejeitando-se majoritariamente a amplitude do sentido que seria preconizada por Paul Otlet (1864-1944). Este estudioso, que realizou pesquisas conducentes ao Traité de la Documentation, de 1934, considera, nessa ocasião, mas embrionariamente já antes, que a bibliologia implica quatro trâmites processuais que constituem outras tantas fases de utilização e tratamento dos documentos (OTLET 1934). O primeiro respeita ao registro da realidade exterior e do pensamento em documentos, enquanto o segundo visa a sua catalografia, descrição e análise. O terceiro aponta para a transformação de documentos simples noutros mais complexos e dos particulares num conjunto articulado. 0 derradeiro momento diz respeito ao registro completo, preciso e exato de dados presentes nos documentos, procedendo-se à respectiva análise e síntese. $\mathrm{Na}$ seção de artigos do periódico dirigido por Fidelino de Figueiredo, essas etapas cumprem-se, de modo mais ou menos explícito, sendo mais consolidadas e extensas as duas primeiras.

\section{Fatos históricos}

Para compreender o modo como na publicação dirigida por Fidelino de Figueiredo são abordados os fatos históricos, convém considerar a obra do historiador britânico E.H. Carr What's History, na qual o autor defendia que havia uma diferença entre os fatos - genericamente identificados com tudo o que tinha tido uma existência situada no espaço e no tempo - e os fatos históricos (CARR s.d.). Na Revista de História, muitos artigos centram-se em exclusivo na publicação de fatos históricos, restringindo os colaboradores do periódico a sua atividade, quase em exclusivo, ao cumprimento de ações de natureza heurística.

Assim, aconteceu preferencialmente em muitos dos artigos referentes a domínios de estudo como a história política, militar e diplomática, da responsabilidade de autores como Pedro de Azevedo, António Baião ou o Abade de Baçal. Nas áreas disciplinares referidas, a visão predominante acerca dos fatos consagra uma historiografia tradicional, na linha de Acton. No periódico dirigido por Fidelino de Figueiredo, os colaboradores da seção de artigos utilizam, na maior parte das vezes, o termo "fato" como sinônimo de "acontecimento", sem disso se darem conta.

Na prática historiográfica dos articulistas da Revista de História, o pendor descritivo da sua narração, aliado ao já referido mimetismo face aos documentos transcritos, contribuiu para a ambiguidade entre fatos e acontecimentos, em busca de alegada objetividade. No entanto, podemos considerar - respeitadas as referidas e necessárias distâncias - que José de Queiroz, quando estudou a deterioração dos azulejos de S. Vicente de Fora, ou Santos Farinha, ao dedicar-se à destruição do Palácio de Palhavã, estavam a tratar como acontecimentos fatos que podiam não ser vistos como tais, mantendo a sua identidade distinta. 


\section{Método}

No periódico dirigido por Fidelino de Figueiredo é impensável a consignação de qualquer exercício de teor metodológico sem que este se estribe majoritariamente em documentos escritos. O termo "método" pode designar o conjunto de procedimentos empregues para atingir determinados objetivos. Na Revista de História não existe um método único, imposto a todos os colaboradores, dotado de um conjunto formalizado e sistemático de regras devedoras de um plano teórico sólido. Ainda assim, na publicação em análise, o escrúpulo documental constituiu um caminho preferencialmente trilhado. Nesta linha, desenvolveu-se o método histórico com Ranke em meados dos Oitocentos, aprofundado e sistematizado pela crítica histórica, colocada em prática por Monod e seus seguidores na França, no seio da escola metódica. Na Revista de História, a mera publicação de documentos prevaleceu face ao respectivo tratamento, sempre muito pouco especializado. Aliás, não existe no periódico nenhum artigo teórico especificamente sobre o método histórico. 0 único esforço intelectual que disso relativamente se aproxima é protagonizado pelos trabalhos de Vieira de Almeida.

A metodologia heurística implica e concita várias atividades. Na Revista de História, o predomínio da publicação de documentos ocorre em detrimento da elaboração de repertórios de fontes, do estabelecimento de uma classificação de depósitos de manuscritos ou da construção de índices, remissivos e outros. A atividade heurística dominante no periódico dirigido por Fidelino de Figueiredo demonstra que o atraso português na organização metódica do patrimônio documental era patente.

\section{O tempo histórico}

Nos artigos publicados na Revista de História o tempo é uma das coordenadas históricas e historiográficas patentes na prática e na escrita dos colaboradores do periódico: "A relação entre o Tempo e a História é tema inesgotável [...]" (GLEZER 2002). No entender de Diogo José Calzans: "[...] já o conhecemos o bastante para vivê-lo de maneira plena e ao mesmo tempo de que, a respeito dele, nada sabemos [...]" (CALZANS 2006, p. 11-12).

Não é simples demarcar uma linha divisória entre a experiência do tempo vivida pelos colaboradores do periódico e o tempo historiográfico. Pode afirmarse que, no fio do tempo vivido entre 1912 e 1928, os eruditos e homens de letras presentes na Revista de História urdiram, cada um a seu modo, uma trama temporal, tanto no plano epistemológico como no plano linguístico. No estudo de Ivan Domingues intitulado o fio e a trama. Reflexões sobre o tempo e a história, o filósofo brasileiro faz questão de explicar o título da obra: "[...]. De um lado, o fio evoca o tempo e põe em relevo a substância intangível com cuja ajuda a História é tecida ou construída [...] a trama designa a História e o seu artífice [...]" (DOMINGUES 1996, p. 11).

No espaço dedicado aos artigos, os colaboradores da publicação dirigida por Fidelino de Figueiredo dedicaram maior atenção a alguns períodos históricos do que a outros. Dentre todos, destacaram-se, no plano quantitativo, os estudos 
sobre a Idade Moderna, no que respeita à história em sentido estrito, e, em relação à época contemporânea, os trabalhos sobre literatura. O periódico em análise é tributário de uma concepção do tempo historiográfico prevalecente desde meados do século XIX, segundo a qual esse tempo se subordina a uma sucessão de fatos. Conforme argumenta Raquel Glezer, "[...] muitos dos historiadores do século XIX estavam preocupados com a ordenação cronológica dos fatos [...]" (GLEZER 2002).

Na publicação em análise, a coordenada tempo apresenta quase sempre estas características: é unidimensional, unidirecional, irreversível e contínua, variando apenas o grau da respectiva explicitação. O tempo histórico, como percepção direta dos eventos cedeu majoritariamente lugar à consideração da dimensão temporal como resultante de um conhecimento historiográfico de natureza mediata e mediatizada, pelo recurso a documentos escritos, estabilizando-se uma não coincidência entre conhecimento e percepção.

No entanto, existem artigos nos quais o trabalho sobre as fontes históricas se torna um instrumento da crença ou da ideologia do cultor de Clio, conforme resulta patente, por exemplo, no estudo de Fortunato de Almeida sobre o Concílio de Trento, ou no de Lúcio de Azevedo sobre os cristãos novos, no que tange às convicções religiosas de cada um. José Reis elaborou um estudo recente, intitulado Sobre o tempo, no qual expôs, em sucessão diacrônica, as diversas concepções que Aristóteles, Plotino, Santo Agostinho, Kant, Husserl e Heidegger desenvolveram acerca da dimensão temporal (REIS 2007, p. 15).

A concepção predominante de tempo na Revista de História e suas características foram parcialmente elencadas por Ivan Domingues, se for descontada a dimensão teórica e metarreflexiva que este convoca na sua postulação genérica:

\footnotetext{
Por um lado, dispondo de um elemento próprio com que operar (o acontecimento), dotada de uma forma própria com que lhe dar a expressão (a narrativa) e submetida a um conjunto de coacções afectas ao real e ao próprio discurso (ater-se ao ocorrido, dispô-lo em séries, organizá-lo em temas ou matérias), a História deverá desenvolver uma techné toda sua para operá-las, com cuja ajuda poderá não só reportar-se ao seu objecto e relatá-lo, sem o risco de se confundir com a narrativa de ficção, como também edificar um plano meta-empírico (teoria) e nele instaurar o tempo histórico, sem assimilá-lo ao tempo da crónica (calendário) ou ao tempo do discurso [...] (REIS 2007, p. 193).
}

A conexão entre tempo e fatos históricos não se extingue no quadro genérico exposto; antes se reforça pela exposição de exemplos concretos que a certificam, plasmando a identidade exposta de modo impressivo.

\section{Verdade histórica: categoria de conhecimento e processo histórico}

A verdade, como conceito operatório, depende de todos os outros estudados até ao momento, influenciando-os e sendo afetada por eles. Pode, teoricamente, ser encarada parcialmente como Elevator Word: "a verdade é um daqueles termos a que o filósofo Ian Hacking chamou elevator words palavras 
que não correspondem a objectos no mundo ou ideias mas que são usadas para dizer algo acerca do mundo [...]" (NUNES 2002, p. 285-315). O caráter central da temática em apreço na filosofia atual é discutido e defendido por Pascal Engel: "A verdade é uma noção filosófica central [...] dependem dela ou estão-Ihe próximas: crença $[\ldots]$; conhecimento $[. .$.$] ; existência ou ser [...];$ facto; possibilidade e necessidade [...]" (ENGEL 2002, p. 1). O nosso plano de abordagem teórica sobre a verdade procura encarar os respectivos modos de fundamentação e as temporalidades envolvidas. Esta terminologia tríplice, que nos serve apenas como guia genérico e indireto, foi sistematizada por Fernando Gil (MARTINS 2002, p. 15-40).

No periódico dirigido por Fidelino de Figueiredo impera uma noção aristotélica de verdade, quase sempre ontológica, ao arrepio da lógica. $\mathrm{Na}$ Revista de História existe uma forte componente empírica de pesquisa documental, que matiza e desvaloriza a subjetividade kantiana na construção do conhecimento. Nessa medida, apenas os documentos permitem chegar indiretamente à realidade, que permanece intocável na sua essência. O perspectivismo encontra-se ausente, e o pragmatismo surge sistematizado apenas nos trabalhos teóricos de Vieira de Almeida em torno da história e da historiografia. Enquanto o primeiro se concentra no que através dela se diz ou quer dizer, o segundo defende a utilidade dela para a vida e preocupa-se com a vontade de verdade. Na Revista de História, ainda que nunca o formalizem, ou sequer verbalizem, os cultores de Clio seguem majoritariamente práticas similares às do modelo realista referido, sendo que a solução de compromisso entre objetividade e subjetividade é menos frequente, comparecendo apenas na investigação de Fidelino de Figueiredo sobre a crítica literária e na obra de Manuel Silva no seu Schema de história local. No que concerne à tipologia, a verdade pode ser absoluta ou relativa, total ou parcial, subjetiva ou objetiva. Todavia, apesar de residual, a verdade como coerência e convicção também comparece, embora se subjugue, quase sempre, a um dispositivo de prova conforme com a existência empírica dos fenômenos. No entanto, os trabalhos de Fortunato de Almeida são paradigmáticos de um hibridismo segundo o qual a posição religiosa do autor superintende a apresentação exaustiva de fontes. Pode considerar-se que na Revista de História não se procura, na maioria dos artigos, verdades universais, resultantes da busca de leis gerais (GUESNERIE 2003, p. 171-186). Fortunato de Almeida realizou um trabalho assente na construção de argumentos probatórios, mas adicionou alguns elementos a essa noção de verdade. Quando escreveu sobre os Portugueses no Concílio de Trento, usou a sua convicção como propriedade que concilia a subjetividade mais livre com uma racionalidade controlada, sobrepondo-se esta àquela. No texto Sobre D. Miguel de Anunciação, Bispo de Coimbra, mantém-se, à superfície, mas de modo impressivo, a procura da prova.

As perspectivas fenomenológica e hermenêutica de verdade, clássicas ou modernas, não recebem particular acolhimento nas páginas da Revista de História. O tipo hermenêutico de abordagem centra-se nos textos para desvendálos ou desvelá-los, de modos diversos. Enquanto para Schleiermarcher havia um 
sentido originário e original de verdade, no entender de Hegel, esta era emanação do espírito, enquanto Dilthey a relacionou com a vida. Qualquer dessas teorias representa passos no sentido de uma hermenêutica renovada, mais ausente da publicação em análise do que as reflexões clássicas em torno da interpretação dos textos (GADAMER 1976). Os ecos heideggerianos na publicação em apreço resultam - pelo menos aparentemente - ainda menores, dado que, para Heidegger, o sujeito implica-se ontologicamente nos textos que produz, condicionando-os pela vivência pessoal que neles insufla. Por outro lado, a verdade não é considerada tendo em conta a sua vertente lógico-semântica (SANTOS 2001).

\section{Apontamentos sobre o modo biográfico}

O modo biográfico identifica-se, sobretudo, com a biografia tradicional, dado que nele predomina a noção clássica segundo a qual o que interessa é o registro cronológico de uma vida ou de várias. Contudo, na maior parte das vezes, esse percurso comparece fragmentado em parcelas, que se subordinam à exploração de determinada função ou faceta dos indivíduos, ou de coletivos, embora predomine a consideração daqueles em detrimento destes. No entender de José Maria Amado Mendes, "Ao falar-se de biografia, convirá acrescentar algo sobre as diversas possibilidades de que o respectivo método se reveste [...]" (MENDES 1992, p. 359).

Dos conteúdos desta breve amostra parece resultar clara a ausência de qualquer prefiguração do que viria a ser a nova biografia, teorizada por Giovanni

40 Levi, portadora de quatro modalidades: prosopografia e biografia modal; biografia e contexto; biografia e casos-limite; biografia e interpretação hermenêutica. A primeira tipologia centra-se numa metodologia quantitativa, apagando o esforço individual em função do coletivo; a segunda estuda preferencialmente os indivíduos, inseridos num contexto histórico. A terceira abordagem focada destaca, em exclusivo, indivíduos encarados como seres especiais. A derradeira dimensão consagra a construção historiográfica levada a cabo pelos estudiosos que acentuam a necessidade de estabelecer nexos dialógicos entre, pelo menos, duas personalidades estudadas. De todas as tipologias, aquela que na Revista de História inconsciente e longinquamente pode aflorar é a que cruza indivíduos com contextos. Todavia, tenta não cair na pulsão hagiográfica, que por vezes é forte, sendo sempre que possível contornada (LEVI 1989, p. 1329-1333). A exemplo do que acontece com os conceitos operatórios abordados neste "andamento", a dimensão interpretativa encontra-se praticamente ausente no modo biográfico na Revista de História.

\section{Considerações finais}

Texto de charneira, $O$ espírito histórico apresentou-se como um dos principais momentos de afirmação pessoal e intelectual de Fidelino de Figueiredo. Nas suas páginas, o autor revelou as preocupações que, à época, perpassavam o seu pensamento. Por um lado, sentiu necessidade, talvez por juventude e pela leitura de bibliografia atualizada, de tentar construir uma síntese daquilo que considerava ser os novos métodos e práticas historiográficas que se desenhavam 
em outros países ou ambientes historiográficos. Sem dúvida, apesar de por vezes ser algo confuso (principalmente na $1^{\text {a }}$ edição), Fidelino criou um dos mais interessantes ensaios de teoria e metodologia historiográfica de então. Concomitantemente, demonstrando uma estreita ligação com o tempo presente e o lugar de historiador, Fidelino apresentou uma proposta de profundo sentido nacionalista, de reforma da sociedade, fazendo um apelo à história como mecanismo de moderação de ação política e social. Como tal, a Sociedade Portuguesa de Estudos Históricos e a sua revista serviriam esse propósito. Apesar das interessantes e significativas propostas programáticas subjacentes à SPEH, a verdade é que a ação concreta da Sociedade foi relativamente limitada. Sem dúvida, o seu grande contributo científico e de difusão de trabalhos em história foi a Revista de História.

No periódico, os diversos instrumentos e conceitos operatórios não são, genericamente, alvos de nenhuma reflexão teórica elaborada, excetuando os esforços de Vieira de Almeida em torno da finalidade e da causalidade. Assim, no que respeita aos documentos históricos, são já vistos como fontes a preservar e não apenas como materiais inertes. No que respeita aos fatos, são quase sempre confundidos com acontecimentos, resultando escassamente elaborados ou construídos pelos historiadores. No entanto, essa elaboração, se existe, apenas se circunscreve a alguns casos. Quanto ao tempo histórico, a sua dimensão linear e objetiva sobrepõe-se ao uso subjetivo e hermenêutico, embora este minoritariamente se insinue. O mesmo diagnóstico serve para a verdade histórica (MOREIRA 2013, p. 1023).

\section{Referências bibliográficas}

AMORA, António Soares. O essencial sobre Fidelino de Figueiredo. Lisboa: INCM, 1989.

BOLETIM DA SOCIEDADE DE GEOGRAFIA, Lisboa, n. 4, 29a série, p. 120125, abr. 1911.

BRITO, Ricardo de. A Sociedade Portuguesa de Estudos Históricos no contexto historiográfico nacional (1911-1928). Dissertação (Mestrado em História Contemporânea), Programa de Pós-Graduação em ..., Faculdade de Letras da Universidade de Lisboa (FLUL), Lisboa, 2012.

CALZANS, Diogo José. Tempo ou não-tempo? Um estudo acerca da experiência do tempo e o não-tempo da experiência. Dissertação (Mestado em Filosofia) - Programa de Pós-Graduação em Filosofia, Pontifícia Universitária Católica, Rio de Janeiro, 2006

CARNEIRO, Mário. O pensamento filosófico de Fidelino de Figueiredo. Lisboa: INCM, 2004.

CARR, E. H. Que é a História? Lisboa: Gradiva, [s.d.]

CATROGA, Fernando. O Republicanismo em Portugal, da formação ao 5 de

Outubro de 1910. Alfragide: Casa das Letras, 2010. 
CORREIA, Hélder. Fidelino de Figueiredo na cultura histórica e política do seu tempo (1889-1927). Dissertação (Mestrado em História Contemporânea) - FLUL, Lisboa, 2002.

DOMINGUES, Ivan. O fio e a trama reflexões sobre o tempo e a história. S. Paulo: Iluminuras, 1996.

ENGEL, Pascal. Truth. Chesham: Acumen Publishing Limited, 2002.

FIGUEIREDO, Fidelino de. O espírito histórico, introdução à biblioteca. Noções Preliminares - Programa. 1 ed. Lisboa: Typ. da Cooperativa Militar, 1910.

. O Espírito Histórico. 2 ed. Lisboa: Livraria Clássica, 1915.

O Espírito Histórico. 3 ed. Lisboa: Livraria Clássica, 1920.

. História dum "Vencido da Vida". Lisboa: Livraria Clássica, 1930.

- Historiografia Portuguesa no século XX, Separata do n. 20 da Revista de História da Universidade de S. Paulo, [s. I.], [s. e.], p. 331-349, 1954.

GADAMER, Hans-Georg. Verité et méthode: les grands lignes d'une herméneutique philosophique. Paris: Éditions du Seuil, 1976.

GLEZER, Raquel. Tempo e história. Revista Ciência e Cultura, v. 54, n. 2, 2002.

GUESNERIE, Robert. Verités et représentations sociales. In : CHANGEUX, JeanPierre (org.). La verité dans les sciences-symposium annuel. Paris: Odile Jacob, 2003, p. 171-186.

LE GOFF, Jacques. Documento/Monumento. História e Memória, Enciclopédia Einaudi, v. 1, p. 535-537,1981.

LEVI, Giovanni. Les usages de la biographie. Annales, Economies, Societés, Civilisations, ano XLIV, n. 6, p. 1325-1336, 1989.

MARTINS, José Cândido de Oliveira. Fidelino de Figueiredo e a crítica da teoria literária positivista. Lisboa: Instituto Piaget, 2007.

MARTINS, Rui Cunha. Modos de verdade (entrevista a Fernando Gil). Revista de História das Ideias, v. 23, p. 15-40, 2002.

MATOS, Sérgio Campos. Consciência história e nacionalismo, séculos XIX e XX. Lisboa: Livros Horizonte, 2008.

MELO, Adélio. Categorias e objectos: inquérito semiótico transcendental. Lisboa: Imprensa Nacional Casa da Moeda, 2000.

NUNES, João Arriscado. Risco, incerteza e regimes de verdade: a patologia tumoral e a biologia do cancro. Revista de História das Ideias, v. 23, p. 285-315, 2002.

MENDES, José Maria Amado. O contributo da biografia para o estudo das elites locais. Análise Social, v. XXVII, (2 e 3), n. 116-117, p. 357-365, 1992. 
MOREIRA, Nuno. A Revista de História (1912-1928): Uma proposta de análise histórico-historiográfica. Tese (Doutorado em História) - Faculdade de Letras da Universidade do Porto, Porto, 2013, 2 v.

OTLET, Paul. Traité de la documentation. Paris: Mundaneum, 1934.

PAUL, Herman. What is a Scholarly Persona? Ten Theses on virtues, skills, and desires. History and Theory, n. 53, , p. 348-371, 2014.

REVISTA DE HISTÓRIA, [s.l.], SPEH, 1912-28, 16 v.

SANTOS, Ricardo Jorge. A verdade de um ponto de vista lógico-semântico. Tese (Doutorado em Filosofía) - Faculdade de Ciências Sociais e Humanas da Universidade de Lisboa, Lisboa, 2001. 